\title{
Self-Esteem Development Across the Lifespan
}

\author{
Richard W. Robins ${ }^{1}$ and Kali H. Trzesniewski ${ }^{2}$ \\ ${ }^{1}$ Department of Psychology, University of California, Davis, and ${ }^{2}$ Institute of Psychiatry, King's College, London, \\ United Kingdom
}

\begin{abstract}
After decades of debate, a consensus is emerging about the way self-esteem develops across the lifespan. On average, self-esteem is relatively high in childhood, drops during adolescence (particularly for girls), rises gradually throughout adulthood, and then declines sharply in old age. Despite these general age differences, individuals tend to maintain their ordering relative to one another: Individuals who have relatively high self-esteem at one point in time tend to have relatively high self-esteem years later. This type of stability (i.e., rank-order stability) is somewhat lower during childhood and old age than during adulthood, but the overall level of stability is comparable to that found for other personality characteristics. Directions for further research include (a) replication of the basic trajectory using more sophisticated longitudinal designs, (b) identification of the mediating mechanisms underlying self-esteem change, (c) the development of an integrative theoretical model of the life-course trajectory of selfesteem.
\end{abstract}

KEYWORDS-self-esteem; development; change; stability

As he was nearing the end of his life, Michelangelo began working on what many people believe to be his most important work, the Florentine Pietà. After working intensely for almost a decade, he entered his studio one day and took a sledgehammer to the sculpture. He broke away the hands and legs and nearly shattered the work before his assistants dragged him away. Why did Michelangelo attempt to destroy one of his greatest creations, a statue that has been described as among the finest works of the Renaissance? Disillusioned and isolated in the last decades of his life, Michelangelo had a heightened sense of perfectionism that was exacerbated by his failure to live up to the expectations of his father, who viewed being a sculptor as akin to being a manual

Address correspondence to Richard W. Robins, Department of Psychology, University of California, Davis, CA 95616-8686; e-mail: rwrobins@ucdavis.edu. laborer. Michelangelo, it seems, had self-esteem issues. Was Michelangelo's low self-esteem normative for someone his age? Was he likely to have been plagued by self-doubts throughout his life? An emerging body of evidence is beginning to offer answers to these kinds of questions.

In this article, we review the current state of scientific evidence regarding the development of self-esteem across the lifespan. ${ }^{1}$ After decades of debate, a consensus is emerging about the way self-esteem changes from childhood to old age. We focus here on two forms of change: (a) normative changes in self-esteem, which reflect whether individuals, on average, increase or decrease over time (assessed by mean differences in self-esteem across age groups); and (b) the stability of individual differences in selfesteem, which reflect the degree to which the relative ordering of individuals is maintained over time (assessed by correlations between self-esteem scores across two time points, i.e., testretest correlations). ${ }^{2}$

\section{THE NORMATIVE TRAJECTORY OF SELF-ESTEEM ACROSS THE LIFESPAN}

As we go through life, our self-esteem inevitably waxes and wanes. These fluctuations in self-esteem reflect changes in our social environment as well as maturational changes such as puberty and cognitive declines in old age. When these changes are experienced by most individuals at about the same age and influence individuals in a similar manner, they will produce normative shifts in self-esteem across developmental periods.

The findings from three recent studies-a meta-analysis of 86 published articles (Trzesniewski, Donnellan, \& Robins, 2001;

\footnotetext{
${ }^{1}$ The focus of this article is on explicit (i.e., conscious) global evaluations of self-worth, not implicit (i.e., unconscious) or domain-specific (e.g., math ability) self-evaluations.

${ }^{2}$ These two forms of change are conceptually and statistically distinct. Individuals in a sample could increase substantially in self-esteem but the rank ordering of individuals would be maintained if everyone increased by the same amount. Similarly, the rank ordering of individuals could change substantially over time without producing any aggregate increases or decreases (e.g., if the number of people who decreased offset the number of people who increased).
} 


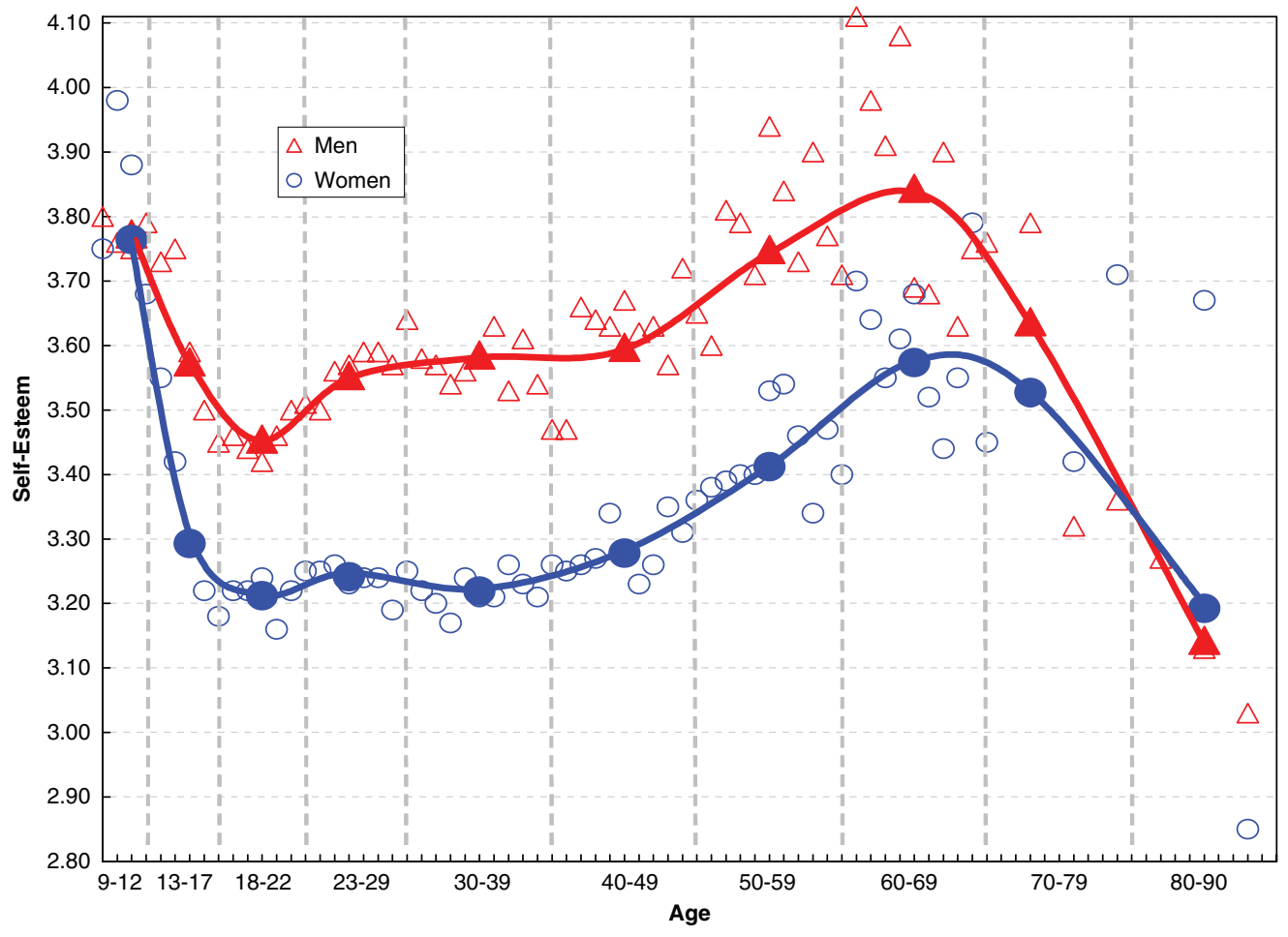

Fig. 1. Mean level of self-esteem for males and females across the lifespan. Also plotted are year-by-year means, separately for males (open triangles) and females (open circles). From "Global Self-Esteem Across the Lifespan," by R.W. Robins, K.H. Trzesniewski, J.L. Tracy, S.D. Gosling, and J. Potter, 2002, Psychology and Aging, 17, p. 428. Copyright 2002 by the American Psychological Association. Reprinted with permisson.

see also Twenge \& Campbell, 2001); a large, cross-sectional study of individuals aged 9 to 90 (Robins, Trzesniewski, Tracy, Gosling, \& Potter, 2002); and a cohort-sequential longitudinal study of individuals aged 25 to 96 (Trzesniewski \& Robins, 2004)_paint a portrait of the normative trajectory of self-esteem across the lifespan (see Fig. 1). Below, we summarize the major changes that occur from childhood to old age.

\section{Childhood}

Young children have relatively high self-esteem, which gradually declines over the course of childhood. Researchers have speculated that children have high self-esteem because their self-views are unrealistically positive. As children develop cognitively, they begin to base their self-evaluations on external feedback and social comparisons, and thus form a more balanced and accurate appraisal of their academic competence, social skills, attractiveness, and other personal characteristics. For example, as children move from preschool to elementary school they receive more negative feedback from teachers, parents, and peers, and their self-evaluations correspondingly become more negative.

\section{Adolescence}

Self-esteem continues to decline during adolescence. Researchers have attributed the adolescent decline to body image and other problems associated with puberty, the emerging ca- pacity to think abstractly about one's self and one's future and therefore to acknowledge missed opportunities and failed expectations, and the transition from grade school to the more academically challenging and socially complex context of junior high school.

\section{Adulthood}

Self-esteem increases gradually throughout adulthood, peaking sometime around the late $60 \mathrm{~s}$. Over the course of adulthood, individuals increasingly occupy positions of power and status, which might promote feelings of self-worth. Many lifespan theorists have suggested that midlife is characterized by peaks in achievement, mastery, and control over self and environment (e.g., Erikson, 1985). Consistent with these theoretical speculations, the personality changes that occur during adulthood tend to reflect increasing levels of maturity and adjustment, as indicated by higher levels of conscientiousness and emotional stability (Trzesniewski, Robins, Roberts, \& Caspi, 2004).

\section{Old Age}

Self-esteem declines in old age. The few studies of self-esteem in old age suggest that self-esteem begins to drop around age 70 (about the age when Michelangelo began working on the Florentine Pietà). This decline may be due to the dramatic confluence of changes that occur in old age, including changes in 
roles (e.g., retirement), relationships (e.g., the loss of a spouse), and physical functioning (e.g., health problems), as well as a drop in socioeconomic status. The old-age decline may also reflect a shift toward a more modest, humble, and balanced view of the self in old age (Erikson, 1985). That is, older individuals may maintain a deep-seated sense of their own worth, but their selfesteem scores drop because they are increasingly willing to acknowledge their faults and limitations and have a diminished need to present themselves in a positive light to others. Consistent with this interpretation, narcissism tends to decline with age (Foster, Campbell, \& Twenge, 2003).

\section{Gender Differences}

Overall, males and females follow essentially the same trajectory: For both genders, self-esteem is relatively high in childhood, drops during adolescence, rises gradually throughout adulthood, and then declines in old age. Nonetheless, there are some interesting gender divergences. Although boys and girls report similar levels of self-esteem during childhood, a gender gap emerges by adolescence, such that adolescent boys have higher self-esteem than adolescent girls (Kling, Hyde, Showers, \& Buswell, 1999; Robins et al., 2002). This gender gap persists throughout adulthood, and then narrows and perhaps even disappears in old age (Kling et al., 1999; Robins et al., 2002). Researchers have offered numerous explanations for the gender difference, ranging from maturational changes associated with puberty to social-contextual factors associated with the differential treatment of boys and girls in the classroom or gender differences in body image ideals. However, no generally accepted integrative theoretical model exists.

\section{RANK-ORDER STABILITY OF SELF-ESTEEM}

Over the past several decades, researchers have debated the degree to which self-esteem should be thought of as a trait-like construct that remains relatively stable over time or as a state-like process that continually fluctuates in response to environmental and situational stimuli. If self-esteem is more state-like over the long term than other personality characteristics, then it may not be a useful predictor of important real-world outcomes.

The findings of a recent meta-analysis support the claim that self-esteem is a stable, trait-like construct (Trzesniewski, Donnellan, \& Robins, 2003). The stability of self-esteem across all age groups, as determined by test-retest correlations, is comparable to that of the major dimensions of personality, including Extraversion, Agreeableness, Conscientiousness, Neuroticism, and Openness to Experience (Roberts \& DelVecchio, 2000). Thus, individuals who have relatively high self-esteem at one point in time tend to have high self-esteem years later; likewise those with low self-esteem earlier in life tend to have low self-esteem later.

However, self-esteem is more stable in some periods of life than in others. Stability is relatively low during early childhood, in- creases throughout adolescence and early adulthood, and then declines during midlife and old age. This curvilinear trend holds for men and women, for U.S. and non-U.S. participants, and for different self-esteem scales.

The lower levels of stability found during childhood and old age may reflect the dramatic life changes, shifting social circumstances, and relatively rapid maturational changes that characterize both the beginning and end of life. For example, during old age, important life events such as retirement and becoming a grandparent may transform one's sense of self, producing higher levels of self-esteem in some individuals and lower levels in others. These life events can lead to lower levels of self-esteem stability if they are experienced at different ages (e.g., some people retire earlier than others) or differentially affect individuals (e.g., only some retirees decline in self-esteem). Moreover, Erikson (1985) noted that as individuals grow older they begin to review their lifelong accomplishments and experiences, leading in some cases to more critical self-appraisals (ego despair) and in other cases to increased self-acceptance (ego integrity). Thus, a developmental shift toward greater selfreflection in old age may produce increases in self-esteem for some individuals but decreases for others.

\section{IMPLICATIONS}

Until recently, the self-esteem literature had been caught in a quagmire of conflicting findings and there was little agreement about the way self-esteem develops. The research reviewed in this article will hopefully move the field toward consensus, and help address questions such as: When in the lifespan is selfesteem relatively high or low? Is self-esteem more like a state (relatively transitory) or more like a trait (relatively unchanging)?

Understanding the trajectory of self-esteem may provide insights into the underlying processes that shape self-esteem development. For example, the fact that self-esteem drops during both adolescence and old age suggests that there might be something common to both periods (e.g., the confluence of multiple social and physical changes) that negatively affects selfesteem.

Knowledge about self-esteem development also has implications for the timing of interventions. For example, the normative trajectory of self-esteem across the lifespan suggests that interventions should be timed for pre- or early adolescence because by late adolescence much of the drop in self-esteem has already occurred. Moreover, developmental periods during which rankorder stability is relatively low may be ideal targets of intervention programs because self-esteem may be particularly malleable during these times of relative upheaval in the self-concept.

\section{CONCLUSIONS AND FUTURE DIRECTIONS}

Research accumulating over the past several years paints an increasingly clear picture of the trajectory of self-esteem across 
the lifespan. Self-esteem shows remarkable continuity given the vast array of experiences that impinge upon a lived life. At the same time, self-esteem also shows systematic changes that are meaningfully connected to age-related life experiences and contexts. These normative changes illustrate the role of the self as an organizing psychological construct that influences how individuals orient their behavior to meet new demands in their environment and new developmental challenges.

Several difficult but tractable issues remain. First, some of the findings reported here require further replication and exploration. In particular, relatively few studies have documented the decline in self-esteem during old age. Establishing the robustness of this effect is important given inconsistent findings in the literature about whether emotional well-being and other aspects of adjustment drop during old age (Mroczek, 2001). In addition, a more fine-grained analysis of age trends might reveal important fluctuations (e.g., changes from early to late adulthood) that were obscured in the present studies.

Second, although the methodological quality of self-esteem research has increased dramatically over the past decade, there is still room for improvement. Greater attention should be paid to measurement issues, including analyses of whether selfesteem scales show different forms of measurement invariance (e.g., does the meaning of self-esteem items vary across age groups?). The use of more representative samples would increase the generalizability of the findings and allow for a deeper exploration into the potential moderating effects of gender, race, ethnicity, and social class. Sophisticated statistical models should be used to better understand dynamic, reciprocal causal influences (e.g., is self-esteem a cause or consequence of important life experiences; e.g., Ferrer \& McArdle, 2003). Cohortsequential longitudinal studies, in which individuals from different age groups are followed over time, are needed to tease apart aging and cohort effects (e.g., will all older individuals develop lower self-esteem or just the particular cohort of individuals who experienced the Great Depression and other life events unique to that cohort?). Finally, genetically informed designs are needed to explore the mutual influence of nature and nurture on self-esteem development; researchers have yet to appreciate the profound implications of the finding that global self-esteem, like most traits, has a genetic basis (e.g., McGuire et al., 1999).

Third, research is needed on the mediating mechanisms underlying self-esteem change. Chronological age has no causal force per se. We need to understand what else changes with age that might produce changes in self-esteem at different developmental periods. One approach is to document the social-contextual factors associated with chronological age, such as the key social roles and events that define and shape one's position in the life course. However, it is important to recognize that such factors can only influence self-esteem through intrapsychic mechanisms, such as perceptions of control and agency and feelings of pride and shame, which shape the way people react to and internalize the events that occur in their lives. In our view, the best way to understand self-esteem development is to understand the self-evaluative mechanisms that drive the self system-that is, the cognitive and affective processes presumed to play a role in how self-evaluations are formed, maintained, and changed. Although experimental studies have linked a number of self-evaluative processes to short-term changes in self-evaluation, we know little about the influence of such processes on self-esteem change over long periods of time. Lifespan research on the self should draw on this experimental work to develop hypotheses about long-term change in self-esteem and explore how selfevaluative processes documented in the lab play out in real-world contexts.

Finally, the literature on self-esteem development lacks an overarching theoretical framework. Most past theoretical work has focused on particular developmental periods (e.g., the transition to adolescence) and particular life domains (e.g., work). Consequently, although the literature has generated a laundry list of possible reasons why self-esteem might drop during adolescence (and why this might be particularly true for girls), there is no integrative model of how the various proposed processes work together to shape self-esteem development. We also do not know whether these same processes can be invoked to account for the drop in self-esteem during old age. Given the complexity of selfesteem development, such a model would necessarily incorporate biological, social, and psychological factors; account for reciprocal and dynamic causal influences; and include mechanisms of continuity as well as change (e.g., various forms of person-environment interaction). Our hope is that, by examining patterns of findings across developmental contexts (childhood to old age) and across life domains (work, relationships, health), the field will move toward an overarching theory of the life-course trajectory of self-esteem.

\section{Recommended Reading}

Harter, S.(1999). The construction of the self: A developmental perspective. New York: Guilford.

Robins, R.W., Trzesniewski, K.H., Tracy, J.L., Gosling, S.D., \& Potter, J. (2002). (See References)

Trzesniewski, K.H., Donnellan, M.B., \& Robins, R.W. (2003). (See References)

Acknowledgments - This research was supported by Grant AG022057 from the National Institute of Aging.

\section{REFERENCES}

Erikson, E.H. (1985). The life cycle completed: A review. New York: W.W. Norton.

Ferrer, E., \& McArdle, J.J. (2003). Alternative structural models for multivariate longitudinal data analysis. Structural Equation Modeling, 10, 493-524. 
Foster, J.D., Campbell, W.K., \& Twenge, J.M. (2003). Individual differences in narcissism: Inflated self-views across the lifespan and around the world. Journal of Research in Personality, 37, 469-486.

Kling, K.C., Hyde, J.S., Showers, C.J., \& Buswell, B.N. (1999). Gender differences in self-esteem: A meta-analysis. Psychological Bulletin, 125, 470-500.

McGuire, S., Manke, B., Saudino, K., Reiss, D., Hetherington, E.M., \& Plomin, R. (1999). Perceived competence and self-worth during adolescence: A longitudinal behavioral genetic study. Child Development, 70, 1283-1296.

Mroczek, D.K. (2001). Age and emotion in adulthood. Current Directions in Psychological Science, 10, 87-90.

Roberts, B.W., \& DelVecchio, W.F. (2000). The rank-order consistency of personality from childhood to old age: A quantitative review of longitudinal studies. Psychological Bulletin, 126, 3-25.

Robins, R.W., Trzesniewski, K.H., Tracy, J.L., Gosling, S.D., \& Potter, J. (2002). Global self-esteem across the lifespan. Psychology and Aging, 17, 423-434.
Trzesniewski, K.H., Donnellan, M.B., \& Robins, R.W. (2001, April). Self-esteem across the life span: A meta-analysis. Poster session presented at the biennial meeting of the Society for Research on Child Development, Minneapolis, MN.

Trzesniewski, K.H., Donnellan, M.B., \& Robins, R.W. (2003). Stability of self-esteem across the lifespan. Journal of Personality and Social Psychology, 84, 205-220.

Trzesniewski, K.H., \& Robins, R.W. (2004). A cohort-sequential study of self-esteem from age 25 to 96 . Poster presented at the Society for Personality and Social Psychology. Austin, Texas.

Trzesniewski, K.H., Robins, R.W., Roberts, B.W., \& Caspi, A. (2004). Personality and self-esteem development across the lifespan. In P.T. Costa, Jr. \& I.C. Siegler (Eds), Recent advances in psychology and aging (pp. 163-185). Amsterdam, the Netherlands: Elsevier.

Twenge, J.M., \& Campbell, W.K. (2001). Age and birth cohort differences in self-esteem: A cross-temporal meta-analysis. Personality and Social Psychology Review, 5, 321-344. 